\title{
The Governance Measures of Bubble Problems in Concrete Members of Slope
}

\author{
Baochu $\mathrm{Yu}^{1, \mathrm{a}}$,Jiasong Wang ${ }^{1, \mathrm{~b}}$, Rongyang Sun ${ }^{2, \mathrm{c}}$, Wenjian Dong ${ }^{1, \mathrm{~d}}$ \\ ${ }^{1}$ Dalian Ocean University,Dalian,Liaoning province,China \\ ${ }^{2}$ No.3 Engineering Company Ltd.Of CCCC First Harbor Engineering Company Ltd.,China

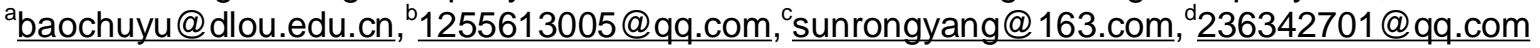

Key words: concrete member; slope surface; bubble governance; slumps

Abstract.Nowadays, concrete has become the most widely used building materials in civil works. The members made of concrete can meet requirements of strength, stiffness and other with regard to the safety of the structure. However, in some high-quality engineering, the bubbles on concrete surface, especially in concrete members of slope, is an intricate problem often encountered by technical personnel. Based on the Hydraulic engineering of COFCO'S Freight Station, two measures of bubble problems in concrete member of slope will be proposed in this paper.

\section{Introduction}

The bubble problem in concrete member of slope is complicated and changeable, which seriously affects apparent quality of the project. By analyzing the causes of bubbles in concrete member of slope, combining with the project of Hydraulic engineering of COFCO'S Freight Station, this paper presents two kinds of methods to solve the bubble problem, which are to regulate slumps and to decrease pouring thickness appropriately. In addition, the concrete members of slope in this project are wave wall and accropode.

\section{Causes of bubbles in concrete member of slope}

Unreasonable material grade, excessive coarse aggregate, much needle and flake aggregate in fine aggregate, etc., all above can bring about free apace of materials due to the shortage of fine materials. Coarse and fine aggregates cannot reach the maximum density, which thus bring out the bubbles. Since water reducer can improve the workability of concrete, decrease the unit water-use and enhance the fluidity of concrete mixture, it is widely used in engineering practice. Therefore, its impact on the bubble cannot be ignored. Entrained air in water reducer is an important influence factor. If concrete contain some large bubbles, water reducer mix some surface-active ingredients with strong air-entraining performance, thus excessively using water reducer will cause more bubbles.

From the perspective of water cement ratio, after concrete reach the water saturation, the excess water freeing to the concrete surface is evaporated and absorbed by concrete itself when curing, thus form the bubbles. So the higher the water-cement ratio is, the bubbles on concrete structure surface will be; otherwise, it is opposite.

In addition to the reasons of material aspects, any link in the construction process of concrete will have an impact on the formation of bubbles, such as the time of mixing station mixing concrete. If the mixing time is insufficient, where has more admixture will form more bubbles, the place did not mix will have the phenomenon of uneven slumps, large slump loss, segregation, etc.; on the contrary, mixing too much will make concrete entrain air, which lead to more bubbles.

Governance measures of bubble problems in concrete member of slope. The above-mentioned problems of raw materials and mixing time are strictly enforced in accordance with the relevant regulations in this project, but the bubbles influencing quality still exist. Therefore, this project focuses on discussing the slump and pouring thickness. 


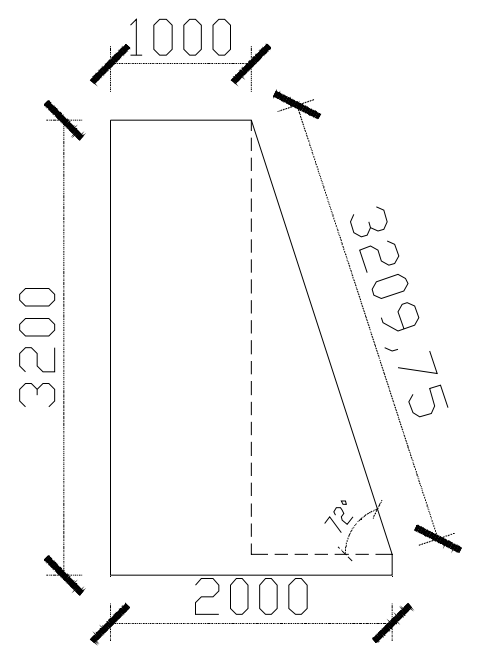

Fig.1 Wave wall

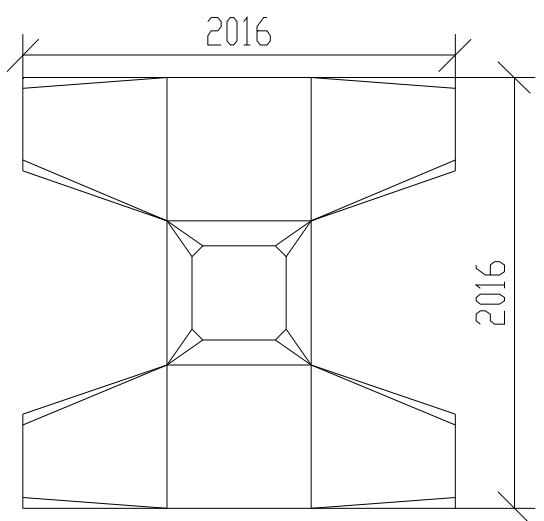

Fig.2 Accropode

Regulate slumps. Slumps refer to the workability of concrete including cohesiveness, water-retaining property and fluidity, which is measured by a quantitative index. Typically, what can be directly known at the construction site are fluidity and cohesiveness. The larger slump is, the greater the fluidity is and the smaller cohesiveness will be; otherwise.

Before constructions, simulation calculations have been performed. In a reasonable economic situation, the maximum value of slump is $140 \mathrm{~mm}$; thus there are five groups of test sections and each group has four test sections and twenty pieces of test samples; the test section is the wave wall of this project, the test samples are cube specimens of $150 \mathrm{~mm} \times 150 \mathrm{~mm} \times 300 \mathrm{~mm}$ and slums are taken: 80 to $100 \mathrm{~mm}, 100 \sim 110 \mathrm{~mm}, 110 \sim 120 \mathrm{~mm}, 120 \sim 130 \mathrm{~mm}, 130 \sim 150 \mathrm{~mm}$. The results of the experiment are shown in table 1:

Table 1 The changes of slumps, surficial area and number of bubbles

\begin{tabular}{|c|c|c|}
\hline Slumps & $\begin{array}{c}\text { Surficial area of members } \\
\text { covered by bubbles }\end{array}$ & $\begin{array}{c}\text { Number of bubbles over } \\
\Phi 1[\mathrm{~mm}]\end{array}$ \\
\hline $80 \sim 100$ & $4.26 \%$ & 182 \\
\hline $100 \sim 110$ & $3,91 \%$ & 163 \\
\hline $110 \sim 120$ & $2.87 \&$ & 122 \\
\hline $120 \sim 130$ & $2.69 \%$ & 66 \\
\hline $130 \sim 150$ & $2.14 \%$ & 54 \\
\hline
\end{tabular}

According to the results, the higher the slump is, the percentage of surficial area of members covered by bubbles and number of bubbles over $\Phi 1 \mathrm{~mm}$ significantly decrease. However, when the slump is more than $120 \sim 130 \mathrm{~mm}$, although the number of bubbles over $\Phi 1 \mathrm{~mm}$ obviously cut down, the percentage of surficial area of members covered by bubbles stay the same. Combined with practical observation, that most bubbles of the moment are fine-mesh affect the appearance, which is caused by vibration. Therefore, the slump of $110 \sim 120 \mathrm{~mm}$ is appropriate.

Decrease pouring thickness appropriately. The number of bubbles produced by clivil concrete has great correlation with the thickness of each pouring, and to decrease the pouring thickness appropriately can obviously improve the bubble problem in concrete. The pouring thickness of concrete shall be determined in accordance with the workability of concrete and the action depth of vibrator. With the continuous densification of concrete, inside excess air float upwards affected by vibration and exhaust in the shape of bubbles. Since inclined template increase the distance of bubbles' exhausting, when bubbles float upwards near to the template, they cannot exhaust vertically due to the obstruction of inclined template. The practical construction shows that to decrease pouring thickness appropriately can reduce the number of bubbles. From an economic viewpoint, the thickness should not be too thin. 


\section{The treatment compare picture of bubble problems in concrete member of slope}
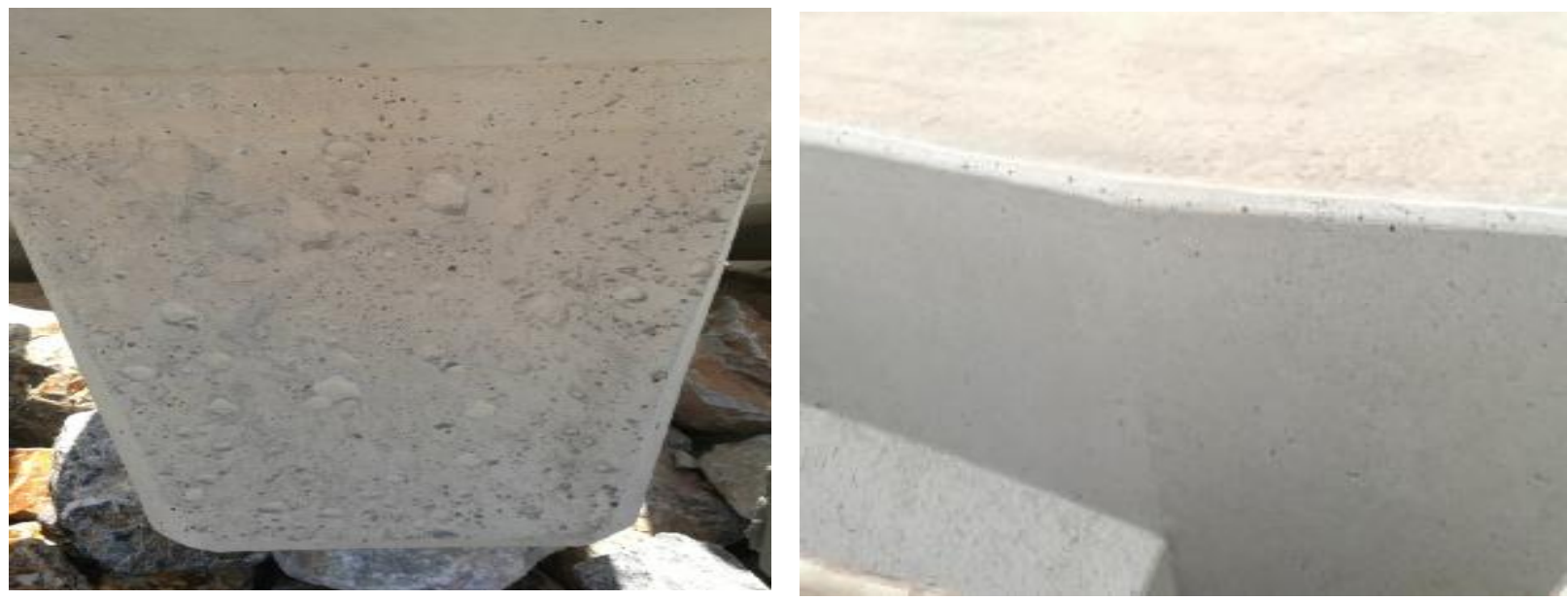

Fig. 3 The accropode picture of before treatment

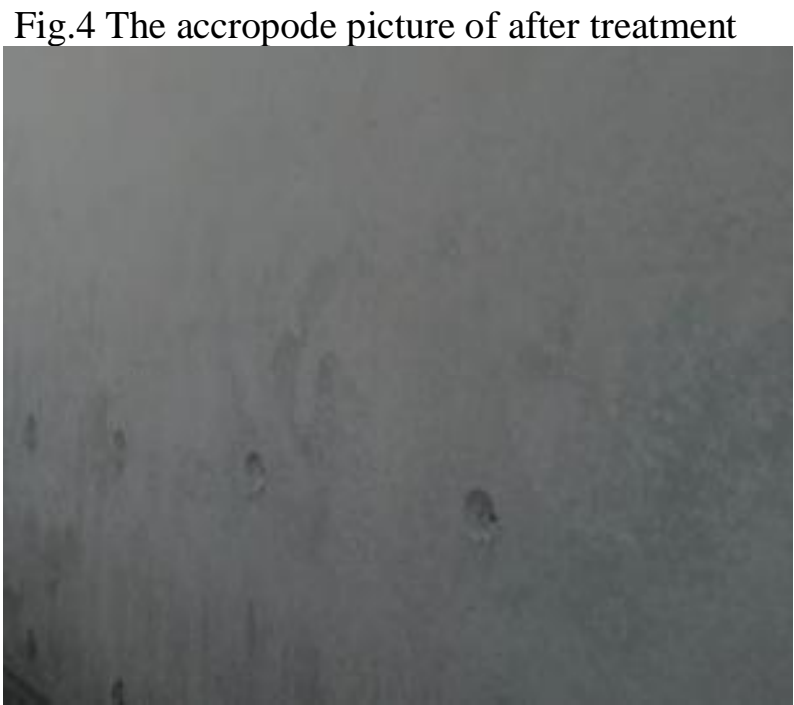

Fig.5 The wave wall picture of before treatment

Fig.6 The wave wall picture of after treatment

\section{Conclusion}

Since the formation of bubbles in concrete of slope run through entire course, this project proves that to regulate slumps and to decrease pouring thickness appropriately can solve the bubble problems effectively. The prevention and treatment of engineering quality problems will never come to an end. In engineering practice, the reasons for the formation of the bubbles in concrete of slope are complicated and multifaceted, so we should flexibly adopt appropriate and effective governance measures to solve different problems.

\section{References}

[1] Tang Chongzheng: Concrete and cement products 2013,p. 75- 77

[2] Zhang Tong,Hu Yang: Building technology 2010 ,p.45-46

[3] Wang Fengqi,Zhou Zhanxue, Wang Haizhen: Construction technique 2005, p.68-70

[4] Wang Guohuai: Architecture and development 2013

[5] Liu Yang: Development orientation of building materials 2012 
2nd International Conference on Advances in Energy, Environment and Chemical Engineering (AEECE 2016)

[6] Song Yujian: Science and technology guide 2014,p.167 